\title{
Studies of meiosis in the intergeneric Hybrids Heuchera $\times$ Tiarella
}

\author{
M. SKALINSKA
}

Institute of Plant Anatomy and Cytology, University of Krakow (received 15.IV.1954.)

Introduction

The present study deals with meiosis in P. M. C's of two intergeneric hybrids between Heuchera sanguinea $\mathrm{E} n \mathrm{~g}$ e $1 \mathrm{~m}$. and Tiarella cordifolia L. The plants originated from crosses executed in the Etablissements Vilmorin in France and were cultivated in the Royal Botanic Gardens, Kew. In 1946 the author had the opportunity to fix for cytological studies the flower buds of these plants. Unfortunately, for vaious reasons the results of this study could not be published earlier.

The two hybrids evidently belonged to different clones; they were totally seed sterile and could be propagated only by cuttings. They differed distinctly from each other in vigour, flower colour as well as the degree of pollen sterility. The first hybrid (plant $\mathrm{RH}$ ) was vigorous and developed abundantly leaves and inflorescences. Its flowers had dark red sepals and bright pink petals. The dehiscence of the anthers was normal in this plant and the proportion of good pollen amounted to 10 to $15 \%$. The second hybrid (plant WH) was notably weaker; it differed from the first one in having greenish sepals and white petals. Most anthers of this plant were non-dehiscent; occasionally however some dehiscent anthers with 3 to $5 \%$ of viable pollen could be found in its flowers.

According to the details given by $\mathrm{R}$ osendahl, Butters and Lakela in their Monograph of the genus Heuchera (1936), the two genera, Heuchera and Tiarella are closely related; Tiarella however has ten stamens contrasting with Heuchera which has only five stamens. The description given by the authors for the intergeneric hybrid Heuchera sanguinea $\times$ Tiarella cordifolia (H. tiarelloides Hort., p. 178) fainly agrees with the features of the two plants studied in the course of the present 
work. In their flowers the second cycle of stamens was more or less developed, their flowers having commonly 7 to 9 stamens (according to $\mathrm{Rosendahl}$ et all. 7 or 8 stamens). Their carpels although more similar to those of Heuchera sanguinea (more inferior than those of Tiarella) had unequal beaks approaching in this respect to Tiarella. On the basis of the above details the two plants investigated could be identified as intergeneric hybrids.

The material for the present studies consisted of young flower buds. They were pretreated in acetic alcohol for a few minutes and fixed in the Navashin's fixative. Microtome sections $13 \mu$ thick were stained with Newton's gentian violet. The somatic chromosome numbers of the two hybrids have been established on mitoses in the floral region.

\section{Somatic numbers of chromosomes}

The two genera Heuchera and Tiarella have been studied cytologically by Schoennagel (1931) and by Skovsted. According to the results obtained by these authors the two genera have the same basic chromosome number $(\mathrm{x}=7)$ Tiarella cordifolia investigated by $\mathrm{S} \mathrm{ch}$ o e n$\mathrm{n}$ a $\mathrm{g}$ e $\mathrm{l}$ has 14 somatic chromosomes; the same number has been established by this author for the second putative parent species, Heuchera sanguinea; this result agrees with that of $\mathrm{Skovsted}$ who studied meioses of this species.

In the course of the present study the somatic number 14 could be confirmed in specimen of $H$. sanguinea of garden origin. The same chromosome number has been established for the two hybrid plants (Fig. 1). Their chromosomes are small; their length in the somatic sets ranges from $1.2 \mu$ to $2.5 \mu$. Distinct subterminal centromeres are observable in most chromosomes.

\section{The anthers of the hybrids}

In the flower buds of the two hybrids a pronounced size difference could be observed between the anthers of the external and internal cycle of stamens; the latter were always smaller and sometimes imperfectly developed. In the external anthers the stages of meiosis were always more advanced; e. g. stages ranging from I Metaphase to II Telophase found in the external cycle coincided with very eraly Prophase (Leptotene) in the anthers of the internal cycle; the occurrence of tetrads or of free primary pollen grains in the external cycle could be stated while the internal cycle contained all stages ranging from early Prophase to II Telophase. 
Studies in the development of the anthers and the course of meiosis in P. M. C's revealed some differences between the two hybrids. In the first hybrid (plant $\mathrm{RH}$ ) the anthers have a nearly normal growth in stages preceding the onset of meiosis. The tapetal ceils are well developed; at I Metaphase in the P. M. C's the tapetal cells have usually a single large nucleus with numerous nucleoli; sometimes bi-nucleate tapetal cells could be found; occasionally mitotic divisions occur in these cells; they show an increased chromosome number, a phenomenon frequently observable in the tapetal layer of various plants. At this stage, owing to a normal increase in size of the pollen sacs, free spaces appear between the P. M. C's which are well filled with cytoplasm and have rounded outlines. On the other hand, in the second hybrid (plant WH) an abnormal development of the anthers could be found in numerous flower buds. Chiefly in the anthers of the internal cycle strong disturbances were frequent; the defective development of these anthers was due presumably to a precocious checking of their growth; in such anthers the tapetal cells early show signs of a premature abortion. The appearance of the P. M. C's in the respective pollen sacs is also abnormal: the cells are polygonal and at I Metaphase they still represent a compact tissue without any intercellular spaces (Figs. 31, 32). It should be noted that in such anthers in addition to the typical meiotic irregularities usually found in hybrids between remote species or distinct genera, some peculiar disturbances are observable in the course of meiosis.

\section{Meiosis in Plant RH}

The study of meiosis in P. M. C's of this plant dealt chiefly with I Meta - Ana- and Telophase as well as II Metaphase with the purpose of studying the degree of pairing of the chromosomes in this intergeneric hybrid.

It should be emphasized that the pairing, although incomplete and variable, was less irregular than it could be anticipated. The frequency of bivalents was rather high, their number ranging from 4 to 7 per cell (Table I). The percentage of bivalents calculated for 32 cells at I Metaphase in a single typical pollen sac amounted to $83,4 \%$ (Table II). A regular equatorial plate was found usually in cells with higher numbers of bivalents; only in some P. M. C's, owing to non-congression and a defective development of the spindle, the bivalents were scattered along the axis of the cell together with the univalents (Fig. 2). Most bivalents show a normal spiralisation; bivalents with one terminal chiasma prevail; ony in a few cells a ring-shaped bivalent with two terminal chiasmata could be discerned. The strongly contracted univalents are almost spherical. 


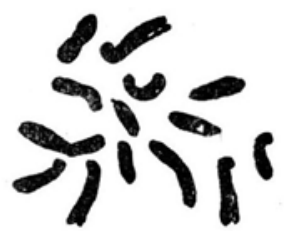

1
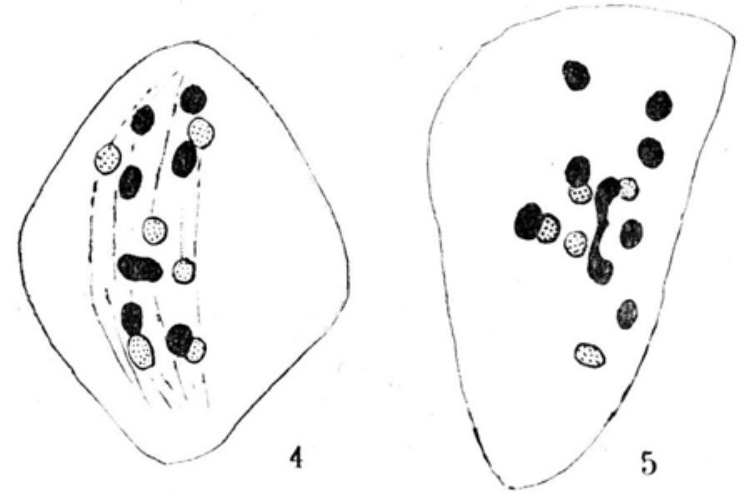
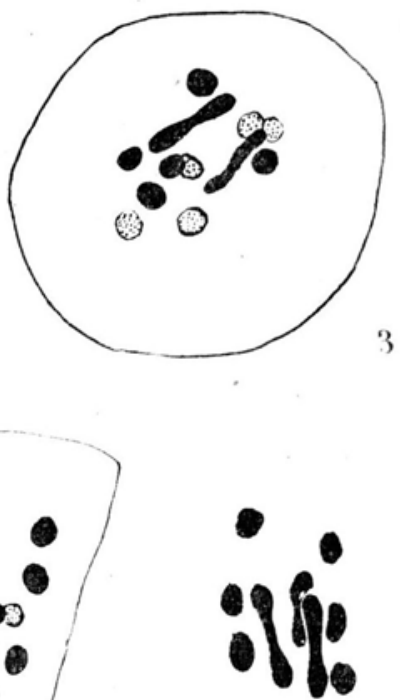

1

6
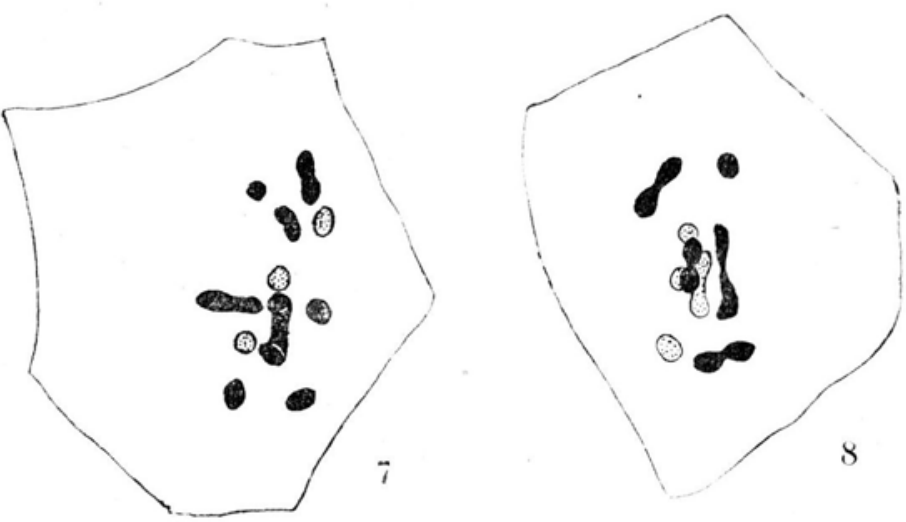

Figs. 1-8. Fig. 1 - somatic plate of the hybrid Heuchera sanguina

Tiarella cordifolia (floral region) (X 4000). - Fig. 2 - I Metaphase (plant RH); 5 pairs, 4 univalents: failure of congression of the bivantels. Fig. 3 - Meta-anaphase (plant $\mathrm{RH}$ ); delayed separation in two bivalents. Fig. 4 - I Metaphase in a normal anther (plant WH); univalents scattered along the bent spindle. Fig. 5 - I. Metaphase in a normal anther (plant MH); 12 univalents. Fig. 6 - I Metaphase in a normal anther (plant WH) 3 bivalents with approximately normal orientation in the equatorial plate, 8 univalents. Fig. 7 - I Metaphase in an abnormal anther of the internal 
Table I

\begin{tabular}{|c|c|c|c|c|c|c|c|c|c|}
\hline \multirow{2}{*}{ Plant } & \multicolumn{8}{|c|}{ Configuration ot chromosomes at I Metaphase } & \multirow{2}{*}{$\begin{array}{l}\text { Total } \\
\text { cells }\end{array}$} \\
\hline & $7_{\text {II }}$ & $6_{\mathrm{II}}+2_{\mathrm{I}}$ & $5_{\mathrm{II}}+4_{\mathrm{I}}$ & $4_{1 I}+6_{I}$ & $3_{\mathrm{II}}+8_{\mathrm{I}}$ & $2_{\mathrm{II}}+10_{\mathrm{I}}$ & $1_{11}+12_{1}$ & $14_{1}$ & \\
\hline RH & 9 & 11 & 9 & 3 & - & $\ldots$ & - & - & 32 \\
\hline WH bud 8 & 2 & 12 & 25 & 25 & 18 & 11 & 5 & 2 & 100 \\
\hline bud 3 & 1 & 6 & 7 & 8 & 6 & 5 & 2 & 1 & 36 \\
\hline bud $\left.7^{*}\right)$ & - & 2 & 2 & 5 & 8 & 9 & 1 & & 27 \\
\hline
\end{tabular}
account.

*) Abnormal anther; only P. M. C's with 14 chromosomes were taken into

In some anthers a continuous series of stages ranging from I Metaphase to I Telophase could be found from the bottom to the top of a single pollen sac. The anaphase separation of the paired chromosomes proceeds synchronously in most cells. In this stage some univalents lagging between the two groups of chromosomes moving to the poles may be observed. It seems probable that some univalents - possibly those occurring near hte poles at I Metaphase - become also incorporated into the daughter nuclei. In some cells at Anaphase a delayed separation of the paired chromosomes was observed (Fig. 3). In such cells the bivalents are stretched between two groups of chromosomes near the poles; it is difficult to estimate whether the chromosomes in these groups

Table II

I Metaphase

\begin{tabular}{|c|c|c|c|c|}
\hline \multirow{2}{*}{ Plant } & \multirow{2}{*}{$\begin{array}{l}\text { Number of } \\
\text { P. M. C's }\end{array}$} & \multicolumn{2}{|c|}{ Number of bivalents } & \multirow{2}{*}{$\stackrel{o}{o}$ of bivalents } \\
\hline & & potential & actual & \\
\hline $\mathrm{RH}$ & 32 & 224 & 186 & 83.4 \\
\hline WH bud 8 & 100 & 700 & 392 & 56.0 \\
\hline bud 3 & 36 & 252 & 140 & 55.5 \\
\hline $\begin{array}{l}\text { bud } 7 \text { (cells with } \\
14 \text { chrs) }\end{array}$ & 27 & 189 & 85 & 44.9 \\
\hline $\begin{array}{l}\text { (cells with abnor- } \\
\text { mal numbers) }\end{array}$ & 17 & 155,5 & 73 & 46.9 \\
\hline
\end{tabular}

$\mathrm{R}$

Explanation to Figs. $7-8-$ continued cycle of stamens (plant WH); 3 bivalents, 8 univalents failure of orientation of the bivalents. Fig. 8 - I Metaphase in the same anther; congression of 4 bivalents; 2 bivalents and 2 univalents lying near the poles. 
represent univalents or already separated pairs; their unequal distribution however suggests that at least some univalents are among them.

At early Telophase in most P. M. C's all chromosomes are grouped on the poles without any lagging chromosomes. In a proportion of cells however strongly stretched univalents were found between the two groups.

In consequence of a rather normal course of the first meiotic division, at Interkinesis most cells have two nuclei; occasionally a small additional nucleus was observable in some P. M. C's. Accordingly, in II Metaphase most cells had two spindles, but sometimes also P. M. C's with three spindles could be found. In some cells differences in the size of the two II Metaphase plates and in their chromosome number could be established; they resulted from an irregular chromosome distribution at I Anaphase. One of such cells is represented on Fig. 23; the two groups have 9 and 5 chromosomes. P. M. C's with single chromosomes lost in the cytoplasm were also found occasionally in this stage. On the other hand, cells containing only one broad spindle formed by restitution or syndiploidy were very rare in this plant. In some pollen sacs in addition to aproximately normal P. M. C's sometimes cells with bridges joining the two II Metaphase plates could be observed; such bridges probably persisted since the I Metaphase (Fig. 35).

In spite of the fact that at II Metaphase some P. M. C's contained 3 spindles which should have given rise to hexads instead of tetrads, the occurrence of more than four microspores in a pollen mother cell was never observed in the respective stage. Most P. M. C's represented normal tetrads; dyads could be also found, but in a very limited number. whereas polyads were not found at all. The above details suggest that in some instances the second division was interrupted leading to the elimination of P. M. C's with an abnormal course of the heterotypic division.

\section{Meiosis in Plant WH}

The course of meiosis in the P. M. C's of this plant differed notably from that already described for plant $\mathrm{RH}$. A large amount of variation in this respect could be observed in different flower buds of this plant. In some anthers the meiotic disturbances were to some extent similar to those observed in plant $\mathrm{RH}$, being typical of hybrids between remote forms (incomplete pairing, lagging of univalents, irregular chromosome distribution during I Anaphase, occasional formation of restitution nuclei etc.). All the above irregularaties however were more frequent and notably stronger expressed in the second plant. In addition, irregularities of a different kind have been found in this hybrid, chiefly in its anthers belonging to the internal cycle of stamens. It has been mentioned 
previously that such anthers frequently manifested a checked growth and a defective development of the tapetal layer; developmental disturbances seem to start in these antherst at very early stage.

Table III

Abnormal anthers; bud 7. - I Metaphase

\begin{tabular}{|c|c|c|c|c|c|c|c|c|c|c|c|c|c|}
\hline \multirow{2}{*}{ Plant WH } & \multicolumn{12}{|c|}{ Chromosome numbers in 45 P. M. C's } & \multirow{3}{*}{$\begin{array}{c}\text { of P. M. C's } \\
\text { w. aberrant } \\
\text { numbers } \\
40\end{array}$} \\
\hline & 12 & 14 & 15 & 16 & 17 & 18 & 22 & 23 & 24 & 25 & c. 34 & .42 & \\
\hline $\begin{array}{l}\text { Number of } \\
\text { P. M. C's }\end{array}$ & 5 & 27 & 1 & 2 & 1 & 2 & 1 & 2 & 1 & 1 & 1 & 1 & \\
\hline
\end{tabular}

One of the abnormalities found in these anthers consisted in the occurrence of P. M. C's with varying chromosome numbers. The chromosome numbers in the P. M. C's range from 12 to c. 34 ; in addition the number c. 42 has been found once in a highly abnormal P. M. C. Cells with aberrant numbers attained in some loculi 40\% (Table III, Figs $13-$ 16). In such cells sometimes all chromosomes are gathered in a single spindle (Figs 13, 14, 29); in other cells they may form two separate groups (Figs 15, 16, 31). Another abnormality. observed in the anthers with a defective development consists in a notably delayed separation of the P. M. C's which at I Metaphase still represent a compact tissue without any intercellular spaces (Figs 31,32); their cell walls are very thin; their shape is irregular and is in a sharp contrast with the hounded shape of P. M. C's in normal anthers. The occurrence of P. M. C's with aberrant chromosome numbers in such abnormal anthers strongly suggests that already pre-meiotic mitoses could have been affected as a consequence of the checked growth and the defective development.

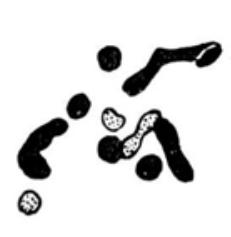

9

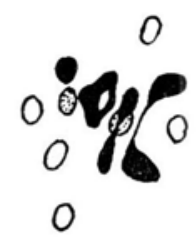

10

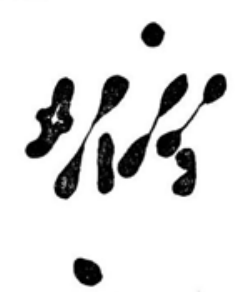

11

Figs 9-11. Fig. 9 - I Metaphase in an abnormal anther (plant WH); 4 bivalents, 6 univalents; complete lack of orientation of the elongated weakly spiralised bivalents (the same as photo fig. 28). Figs 10, 11 - I Metaphase in normal anthers (plant WH); 10 - two bivalents with single terminal chiasmata and a ring-bivalent with two terminal chiasmata; 11 - five bivalents with terminal chiasmata, one bivalent with one non-completely terminalised chiasma and two univalents. 
Detailed studies in the configuration of the chromosomes at I Metaphase in normal and abnormal anthers of this plant have revealed that, on the whole, pairing in P. M. C's was notably lower than in the hybrid $\mathrm{RH}$. As mentioned previously, in the first plant the percentage of bivalents comported $83.4 \%$, whereas in apparently normal anthers of plant WH it attained only $56^{0} \%$ and $55.5 \%$. In abnormal anthers it manifested a still further decrease (Table II). In view of the frequent occurrence in these anthers of cells with aberrant numbers of chromosomes, the data concerning the degree of pairing have been calculated separately for exactly diploid cells and for those with abnormal numbers. In the former the percentage of bivalents amounted to $44.9 \%$, while in the latter it comported $46.9 \%$. P. M. C's with normal numbers show a wide range of variability in respect of the frequency of bivalents: their number ranged from 7 to 0 per cell; cells with 4 or 5 pairs were particularly numerous in normal anthers while in abnormal ones cells with lower numbers of bivalents ( 2 and 3 ) were rather common (Table I).

The formation of the equatorial plate is irregular both in normal and in abnormal anthers. Frequently the plate is not formed even in cells with a relatively high number of bivalents. In some instances the bivalents showed a complete lack of orientation (Figs 7, 9, 28); possibly the spindle failed to develop in such cells. In P. M. C's with low numbers of bivalents or without any bivalents, the univalents are scattered along the spindle (Fig. 4). A high number of univalents is associated in some cells with the occurrence of bent spindles (Fig. 4). In abnormal anthers in most P. M. C's the metaphase plate was very irregular; some bivalents may be unorientated and lie off the plate. In the cell represented on Fig. 7 one of the three bivalents lies across the spindle and another is found far away near one pole; eight univalents are scattered along the spindle. In another cell (Fig. 8) four bivalents form a group at the equator while two others and two univalents are found near the two poles. The same failure of a normal congression of the bivalents could be observed in most cells with chromosome numbers exceeding the normal diploid number (Figs 13-16). In cells with only one group of chromosomes the single spindle may be broad (Fig. 13) or long and attenuated (Fig. 14); bent spindles are relatively frequent. In such spindles the bivalents are mingled together with the univalents and fail to form a regular plate. The same is true of cells with two groups of chromosomes at I Metaphase (Figs 15, 16, 31). A highly abnormal P. M. C. occurring in a group of cells with higher chromosome numbers deserves special mention (Figs 12, 30); it had an unusually high number of chromosomes (c. 42); the chromosomes crowded in the central part of the cell were strongly contracted; neither a regular equatorial plate nor a spindle could be observed; traces of the nuclear 
membrane could be discerned. This abnormal cell manifested some degree of similarity to cells with endomitotically increased chromosome numbers found in some tissues of insects.

The appearance of the bivalents varies considerably. Bivalents with one terminal chiasma prevail; in rare instances bivalents with one not completely terminalised chiasma could be also observed (Fig. 11). The rarest type however is represented by ring-bivalents with two terminal chiasmata (Fig. 10). The bivalents show notable differences also in their degree of spiralisation and their stainability. Some bivalents are normally contracted with almost spherical deeply stained chromosomes. More frequently however owing to their incomplete spiralisation they are weakly stained; their shape is attenuated; they are notably longer than the normally contracted bivalents.

The univalents occurring in a varying number in almost all cells are nearly spherical; they are usually scattered along the spindle. In rare instances cells with exclusively univalents have been found.

The transition from I Metaphase to Anaphase is difficult to trace owing to the frequent occurrence of univalents near the poles and of the stretched weakly spiralised bivalents. In some instances there is a smooth separation of the pairs; sometimes however their separation seems to be delayed and this may lead to restitution.

During early Telophase in most cells two main groups of chromosomes could be discerned; only a few cells however showed a regular or nearly regular distribution of their chromosomes to the poles (Fig. 17): in most cells lagging chromosomes were found in varying but relatively high numbers (Figs. 18, 19, 20). It seems probable that not all univalents become eliminated; those lying near the main groups (as in Fig. 17) may be subsequently incorporated into the daughter nuclei; on the othe" hand those lost in the cytoplasm may form small additional nuclei. Somt univalents lagging after the separation of the two groups of paired chromosomes may possibly move towards the equator; they may be visible there sometimes distnictly stretched (Fig. 19) but presumably they do not divide; they may give rise to additional nuclei or in some instances they may contribute to the formation of restitution nuclei. In consequence, the P. M. C's at interkinesis contain a variable number of nuclei of unequal size. Cells with one nucleus are relatively frequent; in such cells evidently restitution has taken place.

At II Metaphase the number of spindles in the P. M. C's ranges from 1 to 4 . Cells containing two spindles, sometimes with single chromosomes scattered in the cytoplasm, are in prevalence in most anthers. In some loculi however, chiefly in those belonging to the internal cycle of stamens. 

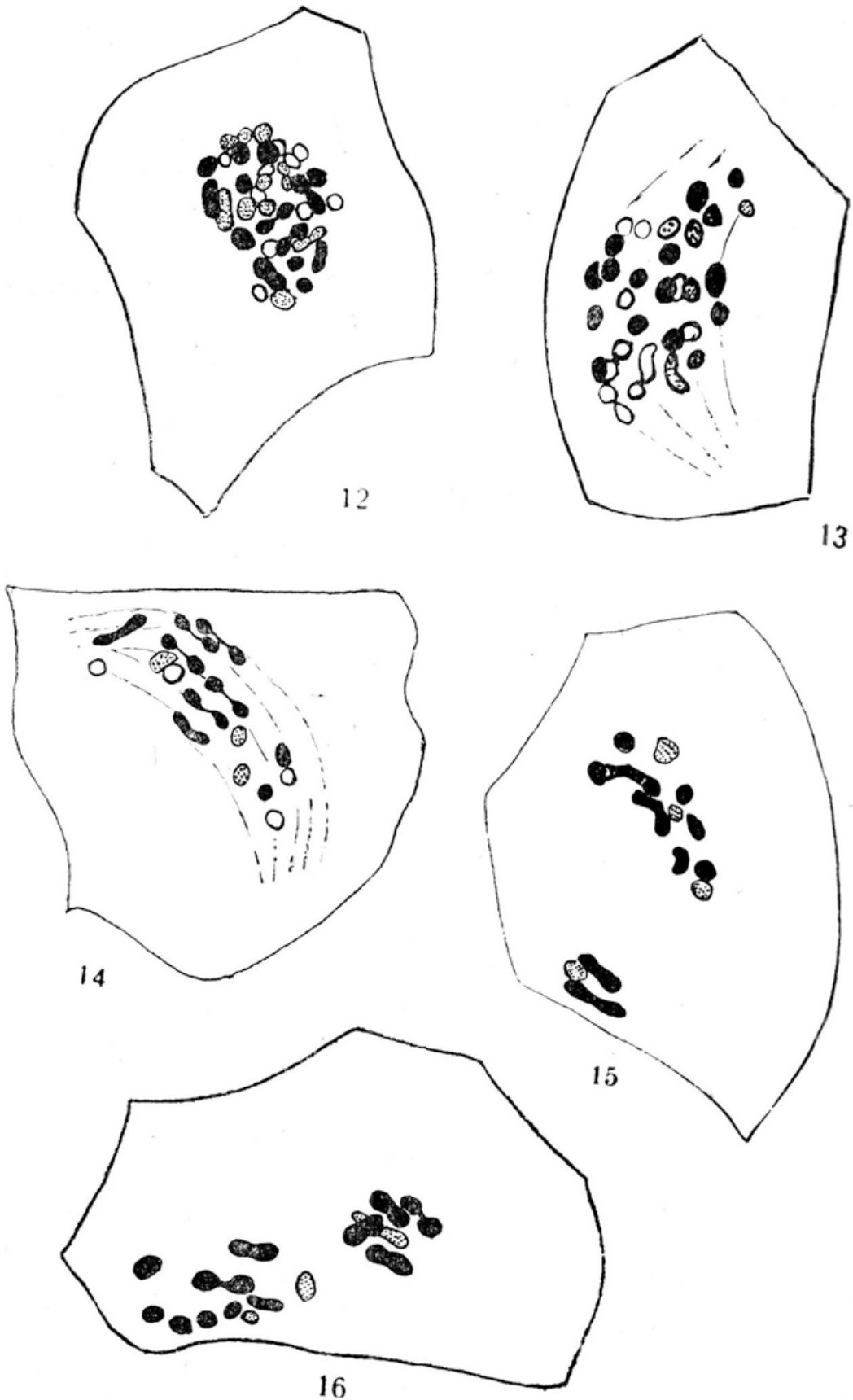

Figs 12-16. - P. M. C's with higher chromosome numbers from abnormal anthers of plant WH. Note the irregular shape of these P. M. C's. Fig. 12 - a highly abnormal P. M. C with c. 42 chromosomes (the same as photo Fig. 30). Fig. 13 - 


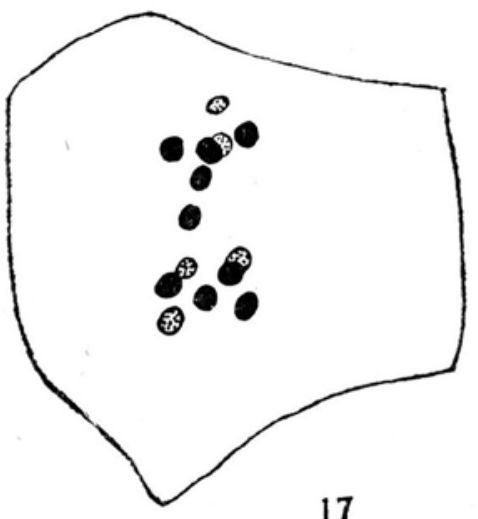

17

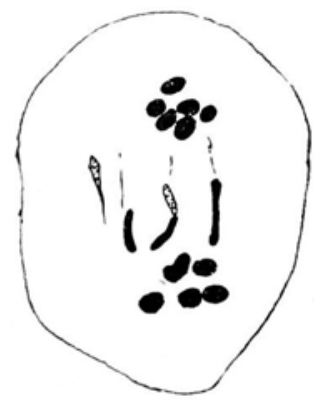

19

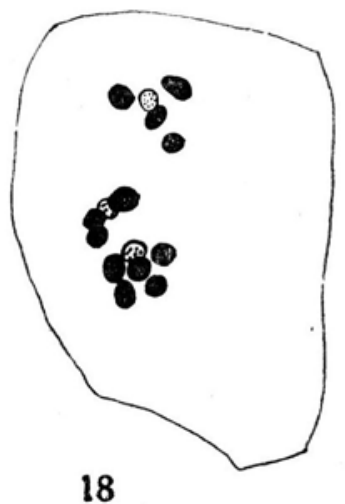

18

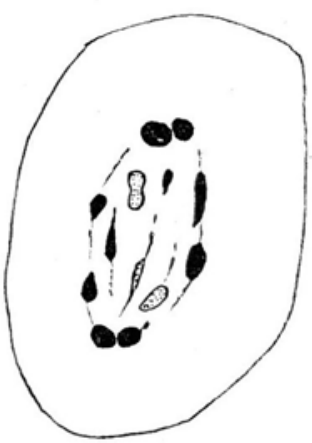

20

Figs. 17-20. Fig. 17 - early telophase in an abnormal anther (plant WH); a nearly regular distribution of the chromosomes (one chromosome somewhat retarded). Fig. 18-20 - I Telophase in a normal anther of plant WH; fig. 18 - irregular dictribution of the chromosomes: a group of four left outside the two major groups;

figs 19, 20 - highly irregular I Telophase with lagging chromosomes.

various strongly expressed abnormalities could be observed. They may be grouped as follows:

1. P. M. C's with one or two additional spindles formed of two, three or four chromosomes (Fig. 22).

2. Cells with an additional minute spindle formed of a single univalent which proved able to develop its own spindle mechanism (Fig. 21).

a P. M. C with 34 chromosomes at I Metaphase; the spindle is bent (the same as photo fig. 29). Fig. 14 - a P. M. C with 23 chromosomes (7 bivalents and 9 univalents) and a bent elongated spindle. Fig. 15 - a P. M. C with 17 chromosomes in two separate groups; the main group has 2 bivalents and 8 univalents and the additional group has 2 pairs and one single chromosome. Fig. 16 - a P. M. C with 23 chromosomes in two groups (the same as photo fig. 31 and 32 ). 
3. In some P. M. C's the two groups of chromosomes may be joined by connections persisting from the first division (Figs 25, 35).

4. In contrast with most P. M. C's which have their chromosomes arranged in well separated groups with distinct spindles, in some anthers lost chromosomes are found in various numbers in the cytoplasm between the two main groups; in such cells sometimes the spindles fail to develop and the second division does not take place.

5. P. M. C's with a single broad spindle, presumably formed by restutition, or in some instances by syndiploidy (Figs 26, 33).

6. P. M. C's with a single giant spindle probably originating from restitution in cells with aberrant, increased chromosome numbers (Figs 27, 34, 37).

The analysis of the II Metaphase in a number of pollen sacs has revealed considerable differences in the occurrence and frequency of these abnormalities in different flower buds and even in loculi of the same anther. In some pollen sacs the majority of the P. M. C's have an almost normal appearance, with two spindles; single chromosomes may be occasionally found in the cytoplasm, however without any spindle fibers; in addition a few cells with a single broad spindle and a low proportion of P. M. C's with 3 or 4 spindles could be found. In other pollen sacs however the latter type prevailed distinctly; also cells with an additional minute spindle were frequent; on the other hand, normal cells with two spindles were less numerous and cells with a single spindle were rare. Still other pollen sacs contained, on the contrary, a remarkably high proportion od P. M. C's with one spindle (Table IV), exceeding 30\%. In some pollen sacs strong abnormalities could be observed in almost all cells; the major groups of chromosomes were partially linked by chromosomes scattered the cytoplasm and the spindles failed in develop. The occurrence of P. M. C's in which the II Metaphase plates were joined by connections persisting since the first division. was not limited to some particular loculi. This rare abnormality could be found both in pollen sacs with nearly normal II Metaphases and in those with the strongest disturbances. It is interesting to note that in some cells the two joined chromosomes (which presumably represented a bivalent in the first division) could be found outside the two plates at II Metaphase (Fig. 36, top left); possibly such configurations could have arisen from bivalents which were unorientated at I Metaphase.

There above details show that in some anthers of a single plant the course of meiosis is relatively more regular than in others. The highest degree of irregularities however could be observed in one particular pollen sac belonging to stamens of the internal cycle. In this pollen sac two types of abnormalities could be observed with a high frequency: the 


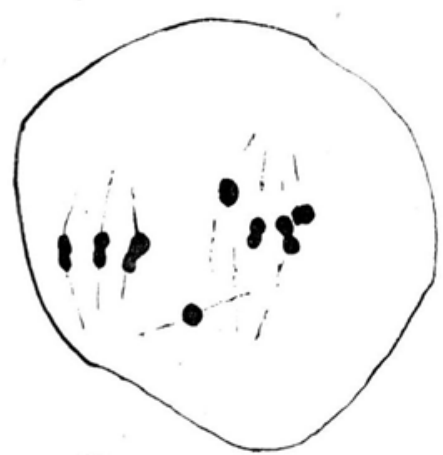

21

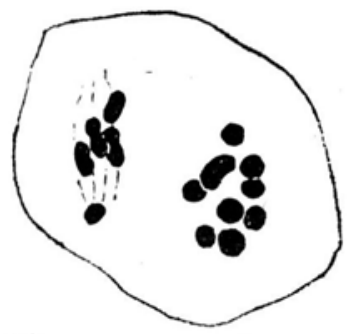

23

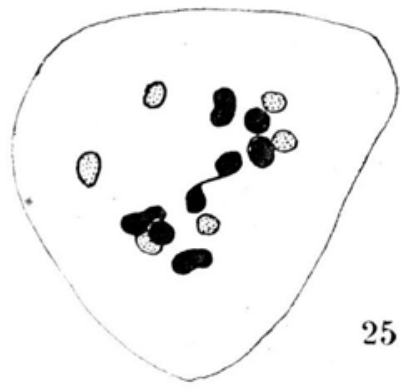

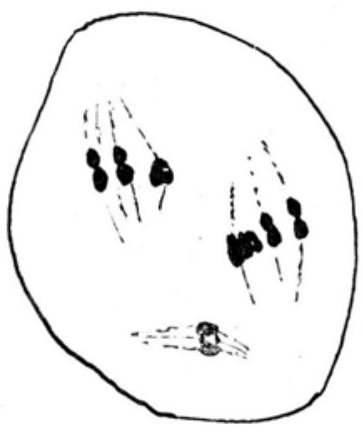

22
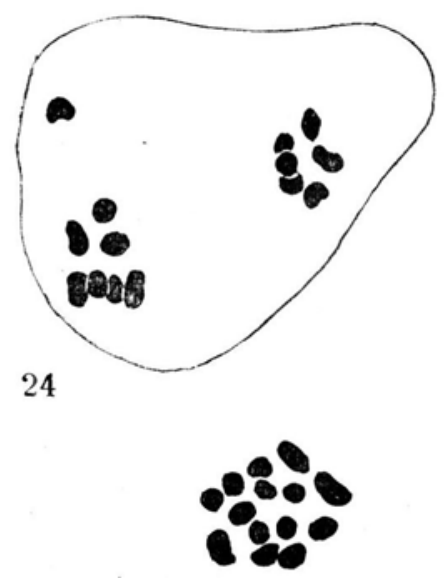

26

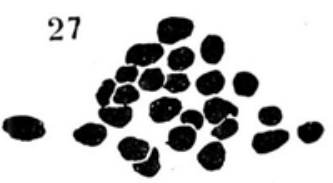

Figs 21-27. Figs .21, 22 - II Metaphase in normal anthers; fig. 21 - a P. M. C with an additional minute spindle of a univalent; Fig. $22-$ a P. M. C with three spindles (plant WH). Fig. 23 - II Metaphase with two plates of unequal size (9 and 5 chromosomes) (plant RH). Fig. 24 - irregular II Metaphase (plant WH); failure of spindles formation. Fig. 25 - II Metaphase (plant WH); the two groups of chromosomes are joined by a connection persisting from the first division. Fig. 26, 27 abnormal anthers of the internal cycle of stamens of plant WH; II Metaphase; fig. 26 - polar view of a single spindle with 14 chromosomes probably from restitution (the same as photo fig. 33); fig. 27 - polar view of a giant spindle with c, 25 chromosomes (the same as photo Fig. 34). 
Table IV

Plant WH. II Metaphase in 150 P. M. C's

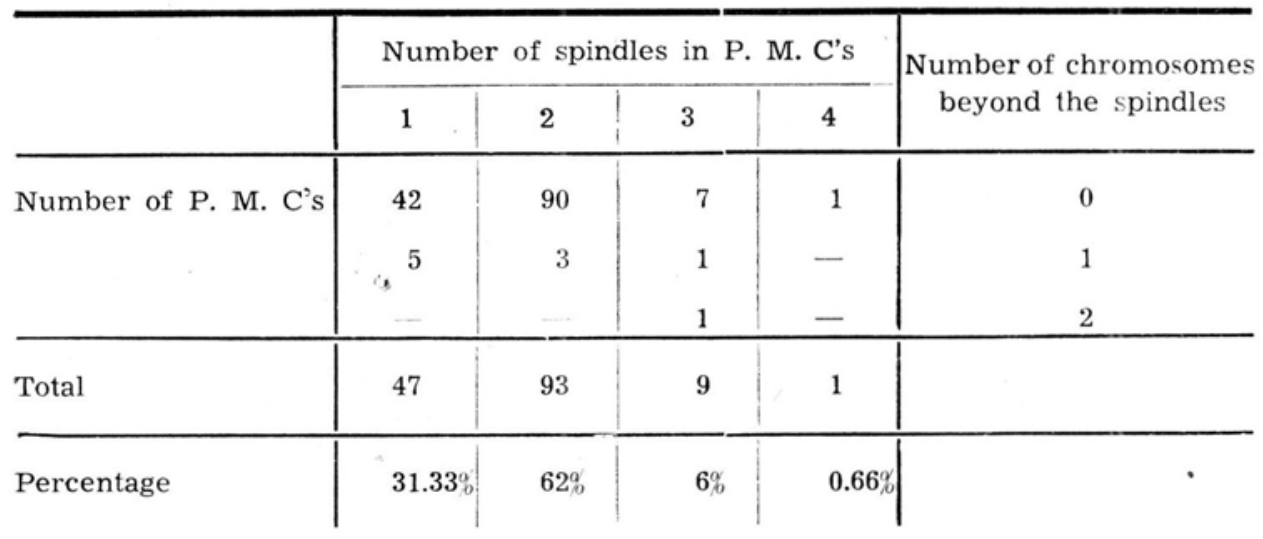

occurrence of groups of diploid cells with restitution nuclei and of cells with higher chromosome numbers. In a series of 11 microtome sections a total of 66 P. M. C's have been studied. Only 7 cells represented the approximately normal type with two spindles; the majority of the cells, namely 43, had single large spindles with 14 chromosomes (Table V, Figs 26, 33); in addition, the rather frequent occurrence of cells with a single giant spindle, thus, with aberrant higher chromosome numbers could be established with certainty (Figs 27, 34, 37); the rarest type is represented by a few cells with aberrant chromosome numbers possessing two spindles. It may be inferred from Table $\mathrm{V}$ that the proportion of cells with higher numbers is unusually high in this particular pollen sac. On the whole, the anther in which these striking abnormalities could be found manifested dinstinct signs of a defective development and of a checked growth; its tapetal cells were in an advanced stage of abortion. It is evident that this defective development could have caused an abnormal course of the first meiotic division leading to the formation of a notable proportion of restitution nuclei in normal (diploid) cells. Presumably however disturbances in earlier stages could have affected the pre-meiotic divisions resulting in the production of a high number of abnormal P. M. C's with increased chromosome numbers; similar cells could be detected already at I Metaphase.

Judging from the configurations found at II Metaphase in this abnormal pollen sac, in the majority of such cells the first division has been omitted; in this stage they have usually a single broad spindle; among 16 P. M. C's with higher chromosome numbers only three were found to have two spindles; the two groups of chromosomes however showed distinct size differences in accordance with the irregular chromosome distribution in cells with numerous univalents. A group of five P. M. C's 
$\mathrm{Table} \mathrm{V}$

Plant WH. II Metaphase in 66 P. M. C's from an abnormal anther

\begin{tabular}{l|c|c|c|c|c|c|c|c|c|c|c}
\hline & Total & \multicolumn{7}{c|}{ Chromosome numbers in P. M. C's } \\
\cline { 2 - 10 } & 12 & 14 & 16 & 20 & 22 & 24 & 25 & 26 & 28 & 34 \\
\hline $\begin{array}{l}\text { P.M.C's with } \\
\text { two spindles }\end{array}$ & 10 & 1 & 5 & 1 & 1 & $1 *$ & - & - & - & & $\left.1^{*}\right)$ \\
$\begin{array}{l}\text { P.M.C's with } \\
\text { one spindle }\end{array}$ & 65 & - & 43 & - & 7 & - & 2 & 2 & 1 & 1 &
\end{tabular}

*) Spindles of unequal size: 7 and 15 chromosomes; 14 and 20 chromosomes

in this abnormal anther is represented on the photo Fig. 37: two giant cells with high chromosome numbers are visible on the right, a third cell of this type is on the left; the cell in the centre is diploid and has a single spindle; on the bottom, a cell with an aberrant chromosome number is found; its two spindles have different chromosome numbers, the upper being approximately haploid and the lower diploid.

In view of the wide range of abnormalities at II Metaphase and of differences in their occurence in various pollen sacs, the result of meiosis varies from cell to cell. In some anthers the II Telophase seems to have a nearly normal course leading to the formation of tetrads and, in addition, of a limited number of dyads, probably produced by restitution in rare instances also some monads have been found. On the other hand, in anthers with strong disturbances (supernumerary spindles, irregular arrangement of the two groups of chromosomes at II Metaphase) a further development was usually interrupted and cells with the above irregularities manifested distinct signs of degeneration sometimes already in II Metaphase; their chromosomes were rather small with a decreased stainability; strong plasmolysis occurred in these stages. The observation of later stages in these loculi presented serious difficulties; II Anaphase could not be detected; the cells seemed to return to a stage similar to Interkinesis before their final degeneration. Sometimes the entire contents of such pollen sacs showed distinct signs of the progressing degeneration, the result of which is the failure of the second division. Thus, polyads which would develop from P. M. C's with additional spindles could not be found in the tetrad stage.

The microspores originating from apparently normal tetrad are able to continue for a short period their development, but ultimately they degenerate, too. Presumably in later stages only dyads which have arisen through the failure of the first division as well as monads which could be found as rare exceptions among the apparently normal tetrads, are 
viable. Cells with giant nuclei in the abnormal anthers undergo a much earlier abortion. Evidently only the dyads and monads give rise to the exceptionally occurring living pollen grains which are notably larger than the normal pollen grains of Heuchera sanguinea. The latter have a diameter of c. $18 \mu$ whereas the diameter of the viable pollen grains of the hybrid WH ranges from 24 to $36 \mu$. Their enlarged size suggests that they represent pollen grains with diploid and possibly tetraploid chromosome numbers.

\section{Discussion}

The most frequent types of intergeneric hybrids have arisen from crosses between two polyploid genera (e. g. Aegilops ovata, $2 \mathrm{n}=28$, and Triticum durum $2 \mathrm{n}=28$, T s c h e r m a k and B le i e r 1926; Gaultheria Shallon, $2 \mathrm{n}=88$, and, Pernettya mucronata, $2 \mathrm{n}=66, \mathrm{C}$ all a n 1941), or alternatively between a polyploid and a diploid species belonging to different genera (e. g. Triticum vulgare, $2 \mathrm{n}=42$, and Secale cereale, $2 \mathrm{n}=14$, Levits ky and B enets k a a 1929). A much rarer type of intergeneric hybrids is represented by cross products of two diploids (e. g. Raphanus sativus, $2 \mathrm{n}=18$, and Brassica oleracea, $2 \mathrm{n}=18, \mathrm{~K}$ a rp e c h e n k o 1927, H o w a r d 1938; Lolium perenne, $2 \mathrm{n}=14$, and Festuca pratensis, $2 \mathrm{n}=14$, $\mathrm{P}$ e t o 1935; Crepidiastrum platyphyllum, $2 \mathrm{n}=10$, and Paraixeris denticulata $2 \mathrm{n}=10$, O no 1941). The hybrids between Heuchera sanguinea and Tiarella cordifolia investigated in the course of the present work also belong to the latter group.

The problem of chromosome pairing at meiosis is in some respect different in diploid and polyploid intergeneric hybrids. Only in the former the chromosome behaviour may throw some light upon the ability of bivalent formation between the chromosomes belonging to two separate genera; on the other hand, in polyploid intergeneric hybrids pairing cannot be considered a reliable test of similarity of the two foreign sets in view of the frequently occurring autosyndesis.

Some diploid intergeneric hybrids show a complete failure of chromosome pairing at meiosis or the pairing is variable and incomplete. The diploid hybrids between Raphanus and Brassica behave in this way. In the $\mathrm{F}_{1}$ hybrid Lolium perenne $\times$ Festuca pratensis however a regular formation of bivalents takes place; the types of Metaphase configurations are very similar to those of both parents and the chiasma frequency is not significantly lower (P e to 1934).

With regard to the ability of pairing the hybrids Heuchera $\times$ Tiarella are intermediate between the two extremes represented by Raphanus $\times$ Brassica with complete asyndesis or a low degree of pairing, and 
Lolium $\times$ Festuca with a regular bivalent formation. In these hybrids pairing, although incomplete and variable, is relatively high. This suggests that the two genera are closely related.

Studies in meiosis in P. M. C's revealed considerable differences between the two hybrids. In the first plant $(\mathrm{RH})$ the percentage of bivalents comported $83.4 \%$, whereas in the second plant (WH) it was notably lower ranging in different flower buds from 44.9 to $56^{\%} \%$. The lowest degree of pairing was observed in abnormal anthers belonging to the internal cycle of stamens. This detail shows clearly that pairing does not depend on the degree of similarity of the chromosome sets; it is evident that in addition some other factors may play a part and may influence considerably the course of meiosis Malnutrition of the P. M. C's in anthers with a defective development of the tapetal layer seems to affect in a considerable degree the chromosome pairing. The weakness of plant $\mathrm{WH}$ and its somewhat retarded development, as compared with the hybrid $\mathrm{RH}$, could have a deletorious influence on the course of meiosis; this influence finds its strongest expression in meiotic disturbances occurring in the imperfectly developed internal cycle of stamens. The importance of nutritional conditions for chromosome pairing has been emphasized by Grant (1952). According to the observations of this author, in the hybrid Gilia millefoliata $\times$ achilleaefolia the degree of chromosome pairing was much higher in plants grown in rich field soil than in plants growing in pure sand; the pairing was notably improved in one and the same plant after the addition of a nutrient solution, and the bivalents were well orientated on the metaphase plate. A frequent failure of a normal congression of the bivalents and their lack of orientation were phenomena frequently observed in the course of meiosis chiefly in anthers of the internal cycle of stamens in plant WH. Other irregularities consisted in a low degree of spiralisation and a decreased stainability of bivalents in some loculi, as well as in an occasional formation of strongly elongated bent spindles. These irregularities are to some extent similar to those encountered in some asynaptic plants of non-hybrid origin. The elongated weakly spiralised bivalents of the hybrid Heuchera $\times$ Tiarella are similar to those of the asyndetic form of Matricaria inodora studied by $\mathrm{V}$ a a r a m a (1950) as well as of the asynaptic line od Pisum sativum described by Koller (1938); a failure of orientation of the attenuated bivalents has been also observed by this author. Elongated bent spindles were described by P r y w e r (1931) in P. M. C's of cultivated strains of Beta vulgaris, var. saccharifera, as well as by $\mathrm{K} \mathrm{u} \mathrm{m} \mathrm{me} \mathrm{r} \mathrm{and} \mathrm{A} \mathrm{b} \mathrm{r} \mathrm{a} \mathrm{h} \mathrm{a} \mathrm{m}$ (1941) in a sterile plant of Sesamum orientale. U p c o t t (1937) has observed similar unusually long and narrow spindles, straight or sometimes bent, in a pollen-sterile form of Lathyrus odoratus. 
In the hybrid plant $\mathrm{WH}$ the occurrence of unorientated bivalents in addition to univalents, as well as the defective development of the spindle at I Metaphase may lead to the formation of restitution nuclei. The latter have been frequently observed chiefly in the internal cycle of stamens in some particular loculi with P. M. C's at II Metaphase. In such abnormal loculi the proportion of cells with single broad spindles at II Metaphase exceeded $30 \%$; this suggests a frequent occurrence of restitution. According to earlier observations of the author on the formation of unreduced pollen grains in Aquilegia (S k a li ń s k a, 1937, 1938) an abnormal retardation of the development leads to some disturbances during meiosis and seems to represent in general favourable conditions for the doubling of chromosomes. In the abnormal anthers of the hybrid Heuchera $\times$ Tiarella in which the tapetal cells early show signs of a premature abortion, restitution and some other meiotic disturbances also seem to be somatically induced; as already mentioned, malnutrition seems to affect in a high degree the course of meiosis.

An interesting abnormality observed in anthers with a defective development is the occurrence of P. M. C's with aberrant numbers of chromosomes; they could be discerned both at I and II Metaphase. In some instances the deviation from the normal diploid number was slight ( 1 to 4 extra-chromosomes or 2 missing chromosomes), in other cases however the chromosomes numbers were higher, ranging from 22 to 34 and in one exceptional cell the number was approximately hexaploid. The occurrence of slight variations in the chromosome numbers of somatic cells has been reported by $\mathrm{Hak}$ ans o n (1950) for the meristems of root tips in some Godetia - hybrids; this variation probably resulted from mitotic irregularities observed by this author in the material studied. Likewise, in root tips of some clones of Poa alpina var. vivipara small deviations ranging from -1 to +3 chromosomes in metaphase plates as well as occasionally occurring abnormal anaphases have been found by the present author ( $\mathrm{Skalinska,1951,} \mathrm{p.} \mathrm{260).} \mathrm{In} \mathrm{the} \mathrm{same} \mathrm{way} \mathrm{the}$ origin of slightly deviating numbers in P. M. C's of the intergeneric hybrid may be explained by the assumption of similar disturbances during premeiotic mitoses.

On the other hand, as regards the other extreme, viz. P. M. C's with numbers approximately twice as high as those in the first group (22 to 34) as well as the hexaploid cell, it seems probable that some other processes have been involved in their formation. The following possibilities should be taken into consideration: 1 . the failure of cell wall formation after some premeiotic mitoses sometimes followed by the fusion of the daughter nuclei; 2. a spontaneous chromosome doubling by restitution during premeiotic mitoses. However, since aneuploid numbers are in prevalence in 
such P. M. C's, the presumable chromosome doubling could have been preceded by disturbances in earlier divisions. Thus, the higher chromosome numbers would be attained in two steps at least; the irregular divisions could have started at an early stage of deveiopment involving several successive cell generations within the abnormal anthers. It should be added however that the mode of formation of a nucleus with the approximately hexaploid chromosome number, as that observed in one cell, is hardly possible to explain in the above way. This single cell had a strange appearance; its chromosomes were strongly contracted and crowded in the centre of the cell without forming any equatorial plate; the nuclear membrane was very indistinct but it seemed to have not completely disappeared; no spindile could be discerned. The nucleus of this cell showed some degree of similarity to endopolyploid nuclei of the testis sheath of the Ortoptera (Whit e, 1945), as well as to polyploid nuclei of the tapetal cells of Spinacia at the stage of endometaphase (W i t k u s, 1945). It should be emphasized however that the increase of the chromosome number from $2 \mathrm{x}$ to $6 \mathrm{x}$ is difficult to explain either by endomitosis or by any other known mechanism of chromosome reproduction. The occurrence of unexpected aberrant chromosome numbers whose origin is extremely difficult to explain has been reported by several authors: M i ckey (1945, cited after Husk $1 \mathrm{~ns}$, 1949) found among spermatogonia and the primary spermatocytes of the grasshopper Romalia microptera cells with hexaploid and pentaploid numbers. $\mathrm{H} \mathrm{u} \mathrm{s} \mathrm{k}$ in s and $\mathrm{S}$ t e in i t z (1948) have detected twice pentaploid cells in differentiated tissues of Rhoeo roots treated by indole-3-acetic acid. In a recently published paper Ols zewska (1952) has described the occurrence of aberrant chromosome numbers (triploid, tetraploid, pentaploid and hexaploid plates) in root tip meristems of Narcissus poeticus; according to this author, the aberrant numbers could have resulted from an irregular chromosome distribution at anaphase or from fusion of nuclei with lower numbers.

It is interesting to note that the occurrence of cells with aberrant chromosome numbers seems to be notably rarer in P. M. C's than in somatic tissues.

\section{S u m m a r y}

The present study deals with meiosis in P. M. C's of two intergeneric hybrids between Heuchera sanguinea and Tiarella cordifolia. The two hybrids were diploid $(2 \mathrm{n}=14)$ They differed distinctly from each other in vigour and the degree of pollen sterility.

In the two hybrids pairing, although incomplete and variable, was relatively high. Considerable differences however were found in the amount of pairing between the two plants: in the first (plant $\mathrm{RH}$ ) the 
percentage of bivalénts at I Metaphase attained $83.4 \%$, whereas in the second (plant WH) it ranged from 44.9 to $56^{\%} \%$ in different anthers. In the latter plant in addition to meiotic disturbances typical of hybrids between remote forms (incomplete pairing, lagging of univalents and irregular chromosome distribution during I Anaphase, ocasional formation of restitution nuclei), irregularities of a different kind were observed. They consisted at I Metaphase in a failure of a normal congression of the bivalents, in their weak spiralisation and lack of orientation, in the formation of abnormal bent spindles, in a high frequency of restitution nuclei in some pollen sacs, as well as in the occurrence in P. M. C's of deviating chromosome numbers ranging from 12 to 34 ; exceptionally also a highly abnormal cell with c. 42 chromosomes has been found. At II Metaphase the number of spindles ranged from 1 (restitution) to 4 . Giant nuclei with increased aneuploid numbers were relatively frequent at this stage in some particular loculi. The very strong meiotic disturbances in the plant WH seem to be somatically induced; chiefly in anthers of the internal cycle of stamen in this very weak plant a precocious checking of growth and a premature abortion of the tapetal cells takes place leading to malnutrition of the P. M. C's. The occurrence of aberrant aneuploid numbers of chromosomes in P. M. C's of such abnormal anthers suggests that already pre-meiotic mitoses were irregular.

\section{REFERENCES}

Calla n, H. G., 1941. The Cytology of Gaulthettya wisleyensis (Marchant) Rehder. A new type of species formation. Ann. of Bot., N. S. 5, 579-585.

Grant Verne, 1952. Cytogenetics of the hybrid Gilia millefoliata $\times$ achilleaefolia. I. Variation in meiosis and polyploidy rate as affected by nutritional and genetic conditions. Chromosoma, 5 372-390.

Hakans o n, A. 1950. Spontaneous chromosome variation in the roots of a species hybrid. Hereditas $36,39-59$.

$\mathrm{H}$ o w a r d H. W. 1938. The fertility of amphidiploids from the cross Raphanus sativus $\times$ Brassica oleracea. Journ of Gen. 36, 239-273.

$\mathrm{H} \mathrm{us} \mathrm{k} \mathrm{i} \mathrm{n} \mathrm{s} \mathrm{C.} \mathrm{L.} \mathrm{1949.} \mathrm{The} \mathrm{nucleus} \mathrm{in} \mathrm{development} \mathrm{and} \mathrm{differentiation} \mathrm{and} \mathrm{the}$ experimental induction of „meiosis“. Hereditas, Suppl. 274-285.

$\mathrm{Husk}$ ins C. L. and $\mathrm{St}$ e i n i $\mathrm{z}$ L. 1948. The nucleus in differentiation and development. II. Induced mitoses in differentiated tissues of Rhoeo roots. Journ. of Her. 39, 66-77.

Karpechenko G. 1927. Polyploid hybrids of Raphanus sativus $\times$ Brassica oleracea, Bull. Appl. Bot. 17, 305-410.

Koller P. C. 1938. Asynapsis in Pisum sativum. Journ. of Gen. 36, 275-306.

$\mathrm{Kummer} \mathrm{L.} \mathrm{and} \mathrm{A} \mathrm{braham} \mathrm{A.} \mathrm{1941.} \mathrm{A} \mathrm{cytological} \mathrm{study} \mathrm{of} \mathrm{sterility} \mathrm{in} \mathrm{Sesamum}$ orientale L. Indian Journ. of Gen. a. Plant Breeding, 1. 41-60. 
I. e vitsky G. A. and B e net s k a y a C. K. 1929. Cytological investigations of constant intermediate rye-wheat hybrids. Proc. U. S. S. R. Congr. in Gen. 2, 345-352.

M i ckey G. H. 1945. Endomitosis in tissues of Romalea microptera. Proc. Louisiana Acad. Scien. 9. 39-57.

O Is ze wska M. J., 1952. Sur la mixoploidie chez Narcissus poeticus L. Acta Soc. Bot. Pol. 21, 685-700.

O no H. 1941. Intergeneric hybridization in Cichorieae. V. Cytologia, 11. 38-352.

Pato F. H. 1934. Cytology of certain intergeneric hybrids between Festuca and Lolium. Journ. of Gen. 28, 113-156.

Pry wer C. 1931. Cytological studies in the sugar-beet. Acta Soc. Bot. Pol. 8, $19-46$. Posendahl, C. C., Butters F. K. and Lakela O. 1936. A monograph on the genus Heuchera. Minnesota Studies in Plant Science, 2, Minneapolis.

Schönnagel, E. 1931. Chromosomenzahlen und Phylogenie der Saxifragaceen. Diss. Kiel.

Skalińska M. 1937. The taxonomical value of two tetraploid groups of Aquilegia. Bibl. Univ. Lib. Pol. Ser. B. $1-34$.

Skalińska M. 1938. Cyto-genetic studies in aneuploid types of Aquilegia. Bull. Acad Pol. Sc., Ser. B. 33-58.

Ska lińska M. 1952. Cyto-ecological studies in Poa alpina L. var. vivipara L. Bull. Acad. Pol. Sc., Ser. B. 1951, 253-282.

Skovsted A. 1934. Cytological studies in the tribe Saxifrageae. Dansk Bot. Arkiv, 8. I.

Tschermak E. und Bleier H. 1926. Utber fruchtbare Aegilops - WeizenBastarde Ber. Deutsch. Bot. Ges. 48, 110-132.

U p c ott, M. 1937. Timing balance at meiosis in the pollen-sterile Lathyrus odoratus. Cytologia, Fuji Jub. Vol. 299-310.

V a a r m a A. 1950. Cases of asyndesis in Matricaria inodora and Hyoscyamus niger. Hereditas 36, 342-362.

White M. J. D. 1945. Animal cytology and evolution. Cambridge Univ. Press.

Witkus E. R. 1945. Endomitotic tapetal cell division in Spinacia. Amer. Journ. of Bot. 32, 326-330. 


\section{EXPLANATION OF PLATE}

All figures represent microphotos of meioses in P. M. C's of the intergeneric hybrids Heuchera sanguinea $\times$ Tiarella cordifolia. The microphotos have been taken with Leitz Makam combined with the Practiflex camera. For all photos a Leitz oil immersion lens 100, N. A. 1.30, and a Leitz periplan eyepiece 10 have been used. Magnification c. $2000 \times$.

Fig. 28 - I Metaphase; unorientated weakly spiralised bivalents; failure of spindle formation (see fig. 9).

Fig. 29 - I Metaphase in a cell with 34 chromosomes; the spindle is bent (see fig 13).

Fig. 30 - I Metaphase; a highly abnormal nucleus with c. 42 chromosomes (see fig. 12).

Figs 31,32 - a group of 4 P. M. C's at I Metaphase in an abnormal anther (photographed at two different foci). The P. M. C's still representing a conpact tissue without intercelllular spaces. Top - a large cell with 23 chromosomes in two groups (see fig. 16). Bottom right - a cell with bivalents and scattered univalents.

Fig. 33 - II Metaphase; polar view of a single spindle with 14 chromosomes probably from restitution (see fig. 26).

Fig. 34 - II Metaphase; polar view of a giant spindle with c. 25 chromosomes (see fig. 27).

Fig. 35 - II Metaphase; the two plates joined by a bridge (plant RH).

Fig. 36 - II Metaphase; top right a P. M. C. with two normal spindles; bottom - a connection between the two spindles; top left - two chromosomes outside the spindles are joined by a connection.

Fig. 37 - II Metaphase; a group of P. M. C's from an abnormal anther: three giant nuclei, one diploid cell (centre), one cell with two plates of unequal size; the first approximately diploid, the second haploid (bottom). 


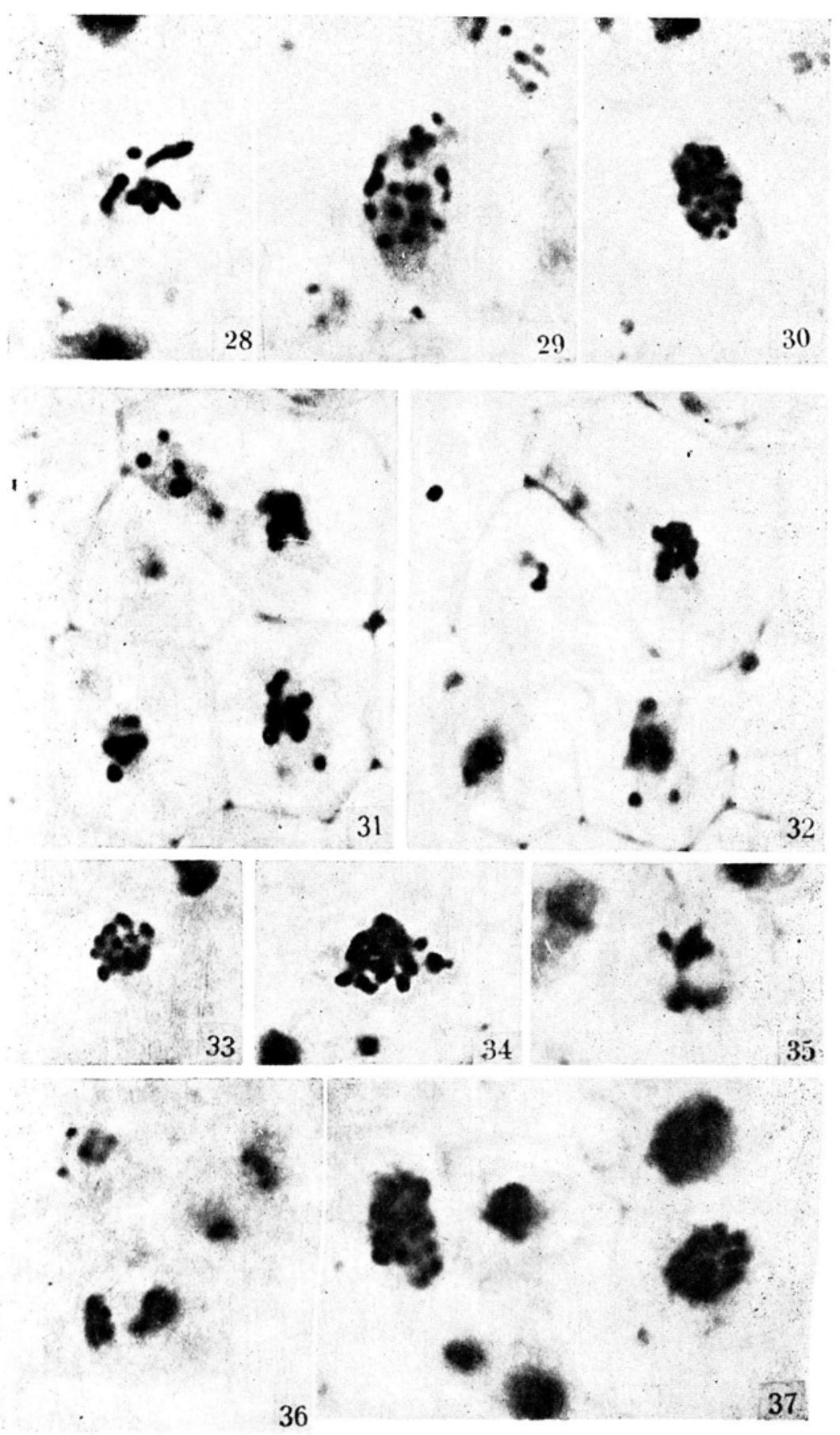

